\title{
DESA SIAGA AKTIF DAN KAMPUNG SIAGA AKTIF WUJUD APLIKASI KLINIK SOSIAL KESEHATAN REPRODUKSI
}

\author{
Syaeful Badar, S.Ag., MA \\ (Dosen dan Penggiat Keselamatan Ibu Hamil Melahirkan) \\ viabadar@yahoo.com
}

\begin{abstract}
ABSTRAK
Kematian Ibu Hamil dan Bayi Baru Lahir yang kita kenal dengan istilah AKI/AKB di Indonesia hingga kini masih menjadi persoalan yang sangat luar biasa, kendati berbagai upaya yang dilakukan oleh pemerintah belum berhasil menekan AKI/AKB. Selama ini persoalan AKI/AKB masih dianggap persoalan pemerintah yang digulirkan juga terlalu banyak melibatkan unsur pemerintah baik dari tingkat pusat sampai daerah peran unsur birokrat sangat dominan, sehingga kenyataan di lapangan program tersebut terkesan hanya papan nama dan retorika seremonial, yang hampir setiap perancangan menghabiskan biaya yang cukup besar. Sementara realitas public dimasyarakat sama sekali kurang di sentuh dan diperhatikan. Inilah yang kemudian menjadi penyebab AKI/AKB di Indonesia semakin bertambah.

Pengalaman adalah guru yang baik, belajarlah dari pengalaman orang lain dan bertanyalah pada orang yang belajar dari realita. Mungkin kata-kata tersebut ada benarnya, artinya kalau program harus berhasil maka belajarlah dari keberhasilan penggalangan masyarakat desa melalui Gerakan Partisipatif Masyarakat dengan proyek percontohan Desa Siaga dan Kampung Siaga dengan mengembangkan Sistem Warga Siaga. Program Desa Siaga dan Kampung Siaga di Kota Cirebon Jawa Barat menjadi alternative rujukan berbagai dinas dan instansi dalam mengembangkan program Kesehatan Ibu dan Anak. Sehingga tidak mengherankan hingga hari Kota Cirebon sering dijadikan daerah kunjungan studi banding program KIA dari berbagai Propinsi, Kabupaten Kota dan Lembaga Asing lainnya.
\end{abstract}

Kata Kunci: AKI dan AKB, Desa Siaga, dan Kampung Siaga; Kesehatan Ibu dan Anak; Gerakan Partisipatif

\begin{abstract}
Deaths of Pregnant Women and Newborn Babies, which we know as AKI / AKB in Indonesia, is still a very extraordinary problem, despite various efforts made by the government that have not succeeded in suppressing AKI / AKB. So far, the issue of AKI / $A K B$ is still considered a government issue which is also rolled out to involve too many
\end{abstract}


elements of the government from the central level to the dominant role of bureaucrat elements, so that the reality on the program's field seems to be just a nameplate and ceremonial rhetoric, which almost every time costs which is quite large. While the public reality in the community is not at all touched and noticed. This is what later became the cause of AKI/AKB in Indonesia.

Experience is a good teacher, learn from other people's experiences and ask people who learn from reality. Maybe the words have a point, meaning that if the program has to be successful, learn from the success of raising the village community through the Participatory Movement of the Community with the Desa Siaga and Siaga Village pilot projects by developing the Alert Residents System. The Alert Village and Alert Village program in the City of Cirebon in West Java is an alternative reference for various agencies and agencies in developing the Maternal and Child Health program. So it is not surprising that Cirebon City is often used as a visiting area for comparative study of MCH programs from various provinces, city districts and other foreign institutions.

Keywords: AKI and AKB Alert Village, and Alert Village; Maternal and Child Health; Participatory Movement

\section{A.Pendahuluan}

Konferensi Kependudukan Dunia tahun 1994 di Kairo, mengeluarkan Konsensus Internasional bahwa setiap Negara wajib memperlihatkan masalah kesehatan reproduksi perempuan, dengan memberi posisi tawar untuk mendapatkan pelayanan kesehatan reproduksi yang prima. Kon-sensus konferensi Kependudukan Dunia, Kairo 1994 "Keadaan sehat yang menyuluruh, meliputi aspek fisik, mental, dan sosial, dan bukan sekadar tidak adanya penyakit atau gangguan di segala hal yang berkaitan sistem reproduksi, fungsinya maupun proses reproduksi itu sendiri. Dengan demikian kesehatan reproduksi menyiratkan bahwa setiap orang dapat me-nikmati kehidupan seks yang aman dan menyenangkan, dan mereka memiliki kemam-puan untuk berproduksi, serta memiliki kebebasan untuk kapan dan seberapa sering meraka ingin berproduksi".

Konvensi ini kemudian membuat dua definisi tentang kesehatan reproduksi, yaitu:

1. Kesehatan reproduksi adalah keadaan kesejahteraan fisik, mental, dan sosial yang utuh dalam segala hal yang berhubungan dengan sistem reproduksi, fungsi-fungsi dan proses-prosesnya.

2. Kesehatan reproduksi merupakan adanya kemampuan orang untuk memperoleh kehidupan seks yang memuaskan dan aman, bereproduksi dan bebas untuk me-mutuskan kapan 
dan seberapa sering mereka akan memperoleh anak.

Sementara WHO (World Health Organization) juga memiliki definisi kesehatan reproduksi tidak hanya berkaitan dengan kesehatan fisik, tetapi juga ke-sehatan mental dan sosial. Sementara pada Deklarasi Alma Ata yang dikeluarkan oleh WHO dan UNICEF tahun 1978 "sehingga setiap orang mampu hidup produktif, baik secara ekonomis maupun sosial" definisi ini menunjukan pentingnya kualitas hidup sebagai kualitas kesehatan masyarakat, terutama perempuan. Bicara kesehatan reproduksi tidak bisa lepas dari persoalan perempuan sebagai bagian dari sumber daya manusia. Perempuan sebagai sumber daya manusia perlu memiliki kesadaran atas reproduksinya secara biologis maupun sosial agar perempuan mampu lebih jauh memahami hak-hak tubuh dan peran sosialnya. Pengertian kesehatan reproduksi perempuan pada akhirnya mencakup serangkaian proses sistem kerja reproduksi yang melibatkan alat dan fungsi reproduksi perempuan, serta aspek sosial yang me-nyertainya. Kesehatan reproduksi perem-puan juga ditentukan oleh proses kehidupan perempuan sejak mereka dikandung, bayi, anak-anak, remaja, dewasa dan ketika menjadi lansia. Masalah reproduksi tidak bisa dilepaskan dari seksualitas dan tubuh manusia, walaupun seksualitas bukan semata dorongan naluri atau kebutuhan biologis (khususnya alat kelamin) tetapi merupakan bentuk interaksi sosial atau bersifat rasional. Mari kita mengingat kembali tentang hak, kesehatan, dan reproduksi.

Kalau di definisikan bahwa kesehatan reproduksi ialah sekumpulan metode, teknik dan pelayanan yang mendukung kesehatan dan kesejahteraan reproduksi melalui pencegahan dan penyelesaian masalah kesehatan reproduksi yang mencakup kesehatan seksual, status kehidupan dan hubungan perorangan, bukan semata konsultasi dan perawatan yang bertalian dengan reproduksi dan penyakit yang ditularkan melalui hubungan seks. Adapun tujuan kesehatan reproduksi adalah memenuhi kebutuhan-kebutuhan re-produksi yang mengalami perubahan sepanjang siklus hidup dan melakukan hal itu dengan cara yang peka terhadap keanekaragaman keadaan masyarakat setempat. Untuk mencapai tujuan tersebut maka pemerintah adalah pihak yang bertanggung jawab, karena negara harus berusaha untuk menyediakan, melalui sistem pemeliharaan kesehatan primer, kesehatan reproduksi untuk semua pribadi pada usia yang tepat secepat mungkin dan tidak lebih lambat.

Kita sepakat bahwa masalah kesehatan reproduksi ternyata tidak 
hanya aspek klinis, tapi aspek sosial juga sangat mempengaruhi. Kita sadar bahwa persoalan kesehatan reproduksi tidak bisa lepas dari konteks sosial, dimana reproduksi di-pengaruhi dan mempengaruhi nilai, etika, agama dan kebudayaan. Dalam makalah ini penulis tidak ingin terjebak pada persoalan penyelesaian yang menggunakan pendekatan klinis dan medis, karena penulis sadar atas kemampuan yang di miliki, sebab penulis bukanlah ahli medis atau petugas kesehatan, apalagi seorang dokter. Penulis dalam makalah ini akan menggubakan media pembelajaran melalui pendekatan kultur yang meliputi sosial dan budaya, atau berdasarkan pengalaman penulis yang hampir 5 tahun aktif di Warga Siaga. Dalam makalah ini penulis akan memaparkan tentang konsep Desa Siaga/Kampung Siaga yang merupakan bagian dari Warga Siaga, yaitu sebuah gerakan partisipasi masyarakat dalam upaya menekan angka kematian ibu hamil bersalin dan bayi baru lahir, yang merupakan bagian dari kesehatan reproduksi. Desa Siaga atau Kampung Siaga merupakan upaya sosial dalam membantu, merespon dan memfasilitasi serta membangun kesadaran kesehatan reproduksi bagi masyarakat. Bisa jadi Desa Siaga/Kampung Siaga merupakan wujud aplikasi klinik sosial dalam membangun kesadaran kesehatan masyarakat untuk berprilaku bersih dan sehat, termasuk kesehatan reproduksinya.

\begin{tabular}{|c|c|c|}
\hline HAK & SEHAT & $\begin{array}{c}\text { REPRO } \\
\text { DUKSI }\end{array}$ \\
\hline $\begin{array}{c}\text { Kewenanga } \\
\text { n yang } \\
\text { melekat } \\
\text { pada diri } \\
\text { untuk } \\
\text { melakukan } \\
\text { atau tidak } \\
\text { melakukan, } \\
\text { memperole } \\
\text { h atau tidak } \\
\text { memperole } \\
\text { h sesuatu. } \\
\text { Kesadaran } \\
\text { hak sebagai } \\
\text { manusia } \\
\text { dan sebagai } \\
\text { perempuan, } \\
\text { merupakan } \\
\text { kekuatan } \\
\text { bagi } \\
\text { perempuan } \\
\text { untuk } \\
\text { melakukan } \\
\text { berbagai } \\
\text { aktivitas } \\
\text { bagi } \\
\text { kepentinga } \\
\text { n diri, } \\
\text { keluarga } \\
\text { dan }\end{array}$ & $\begin{array}{c}\text { Arti sehat } \\
\text { dan sakit } \\
\text { tidak hanya } \\
\text { berkaitan } \\
\text { ketidaknyam } \\
\text { anan fisik, } \\
\text { tetapi juga } \\
\text { mental dan } \\
\text { sosial. Ketiga } \\
\text { aspek ini } \\
\text { saling } \\
\text { berhubungan } \\
\text { satu sama } \\
\text { lainnya, dan } \\
\text { saling } \\
\text { mempengaru } \\
\text { hi, yang } \\
\text { dapat } \\
\text { membuat } \\
\text { seseorang } \\
\text { sakit atau } \\
\text { sehat. }\end{array}$ & $\begin{array}{c}\text { Reproduk } \\
\text { si adalah } \\
\text { menghasi } \\
\text { lkan } \\
\text { kembali } \\
\text { atau } \\
\text { kemampu } \\
\text { an } \\
\text { perempua } \\
\text { n untuk } \\
\text { menghasi } \\
\text { lkan } \\
\text { keturunan } \\
\text { secara } \\
\text { berulang. }\end{array}$ \\
\hline
\end{tabular}


masyarakat.

Dari tabel tersebut diatas bila di definisikan maka makna hak kesehatan reproduksi menjadi dua konsep yang tidak terbatas pada persoalan medis organ reproduksi, sehingga akan muncul tentang hak reproduksi dan kesehatan reproduksi seperti berikut.

\begin{tabular}{|l|l|}
\hline \multicolumn{1}{|c|}{ HAK } & \multicolumn{1}{|c|}{ KESEHATAN } \\
REPRODUKSI & \multicolumn{2}{c|}{ REPRODUKSI } \\
\hline Perempuan mem- & $\bullet$ Perempuan ter- \\
punyai & hindar dari ber- \\
kewenang-an & bagai macam \\
yang melekat & pe-nyakit \\
dalam dirinya un- & menular seksual \\
tuk mempunyai & dan penyakit \\
ke-turunan atau & ke-lamin. \\
tidak serta & $\bullet$ Punya pola hu- \\
melakukan atau & bungan yang \\
tidak me-lakukan & sehat. \\
seluruh rangkaian & Dapat \\
kegiatan yang & menikmati \\
berhubungan & hubungan seks. \\
dengan pengem- & -Memiliki akses \\
bangan keturunan & terhadap pe- \\
tersebut. & layanan \\
& kesehatan. \\
\hline
\end{tabular}

\section{B. Desa Siaga Aktif dan Kampung Siaga Aktif}

Penulis dalam jurnal ini akan memaparkan dua sistem gerakan partisipasi masyarakat, yang melibatkan langsung masyarakat dalam upaya menekan Kematian Ibu dan Bayi Baru Lahir, yang hingga kini masih merupakan persolan dunia internasional yang belum mampu di selesaikan. Dalam proyek pengembangan gerakan partisipasi masyarakat dengan model program yang dikembangkan adalah Desa Siaga dan Kampung Siaga. Desa Siaga merupakan wujud gerakan partisipasi masyarakat Desa dalam upaya meningkatkan kesehatan perempuan serta sebagai bagian dari kehidupan masyarakat desa dalam membangun kesepakatan bersama untuk menyelamatkan ibu hamil dan bayi. Desa Siaga berada di tingkat desa atau di Pemerintah Kabupaten. Sedangkan Kampung Siaga adalah gerakan partisipasi masyarakat yang dibangun atas kesepakatan bersama antara masyarakat, untuk bersama meningkatkan kesehatan ibu hamil dan bayi sebagai upaya mengurangi resiko selama masa kehamilan, melahirkan dan nifas serta mewujudkan partisipasi masyarakat dalam menekan kematian ibu hamil dan bayi baru lahir. Kampung Siaga berbasis masyarakat yang ada di tingkat RW atau Rukun Warga di sebuah Kelurahan pada sistem Pemerintahan Kota. Sehingga bila di bedakan kalau Desa Siaga berada di Desa dalam sebuah Pemerintahan Kabupaten, sementara Kampung Siaga 
berada di Rukun Warga atau RW dalam sebuah Pemerintahan Kota.

Desa Siaga/Kampung Siaga merupakan gerakan partisipasi masyarakat dalam mengidentifikasi permasalahan yang di hadapi di lingkungan masyarakatnya, dengan melibatkan langsung masyarakat sebagai subjek dan objek yang diperankan dalam sistem membangun partisipasi publik. Sebagai percontohan saya akan menceritakan kegiatan Warga Siaga dan Aliansi Pita Putih dalam upaya menekan AKI dn AKB melalui Klinik Sosial, Gerakan Desa Siaga dan Kampung Siaga di Cirebon selama ini berperan sebagai lembaga fasilitator dalam membangun gerakan partisipasi masyarakat dalam me-nekan angka kematian ibu hamil me-lahirkan dan angka kematian bayi baru lahir, yang hingga kini di Kota Cirebon masih tinggi, data terakhir hingga Juli 2005 sudah 3 orang, tahun 2004 mencapai 11 orang ibu meninggal saat melahirkan dan 40 bayi yang meninggal. Pada tahun 2003 bisa jumlah kematian ibu hamil mencapai 14 orang ibu. Kota Cirebon yang hanya memiliki luas wilayah kurang lebih 3.735,8 hektar atau sekitar kurang lebih 37,35 kilo-meter persegi, dengan fasilitas sarana kesehatan yang cukup banyak memadai seperti terdapatnya RSUD Gunung Djati, RSU Swasta Pelabuhan, RSUT Ciremai, RSU Swasta Budi Luhur, 21 Puskesmas, 15
Puskesmas Pembantu, 2 Puskesmas PONED (Pelayanan Obsetri Neonathal Esensial Dasar). Memiliki 4 RSB, yaitu RSB Panti Abdi Dharma, Sumber Kasih, Putra Bahagia dan RSB Muhammadiyah, serta memiliki kurang lebih 10 Rumah Bersalin yang tersebar di Kota Cirebon, dan juga memiliki tenaga bidan yang sudah mengikuti pelatihan APN (Asuhan Persalinan Normal) serta membuka praktek bidan di rumah di luar jam kerja. Penanganan secara medis dalam menekan AKI/AKB di Kota Cirebon ternyata tidak menemukan kendala, karena hampir segala sarana dan fasilitas kesehatan cukup tersedia dan buka hampir selama 24 jam sehari. Namun yang menjadi pertanyaan "Kok AKI/AKB masih cukup dominan di Kota Cirebon?"

Ternyata untuk meningkatkan derajat hidup sehat dan sejahtera di masyarakat, faktor perilaku sangat dominan di samping faktor penyediaan sarana pelayanan ataupun faktor keturunan. Ada 4 faktor yang mempengaruhi peningkatan derajat kesehatan masyarakat, yaitu:
1. Faktor Keturunan
$: 5 \%$
2. Faktor Pelayanan/Sarana
$: 20 \%$
3. Faktor Perilaku $35 \%$
4. Faktor Lingkungan $: 40 \%$

Menyadari bahwa factor perilaku dan lingkungan sangat dominan dalam 
mem-pengaruhi peningkatan derajat kesehatan, maka perlu adanya gerakan yang melibatkan masyarakat secara langsung, baik sebagai objek maupun subjek yang disejajarkan peran dan fungsinya dalam meningkatkan derajat hidup sehat dan sejahtera. Maka melalui gerakan Desa Siaga dan Kampung Siaga kami mencoba me-nawarkan pola partisipasi masyarakat yang tersusun berdasarkan hasil kesepakatan bersama. Desa Siaga dan Kampung Siaga merupakan bagian dari sistem Warga SIAGA:

1. SIAP $=$ Mencatat jumlah ibu hamil di lingkungan tempat tinggal. Me-nyiapkan tabungan buat ibu hamil dan melahirkan. Menyiapkan calon pendonor darah.
2. ANTAR $=$ Menyiapkan transportasi menuju tempat persalinan.

3. JAGA $=$ Menganjurkan suami men-dampingi istri pada masa kehamilan, persalinan dan 40 hari setelah persalinan. Menemani ibu hamil pada masa persalinan. Menganjurkan ibu memberikan ASI ekslusif pada bayi.

Desa Siaga dan Kampung Siaga juga merupakan bagian dari program SIAGA:

a. SIAP =

1. Antisipasi tanda bahaya kehamilan seperti: pendarahan, keracunan kehamilan (tensi tinggi dan pembengkakan serta infeksi).

2. Damping istri ke bidan untuk periksa kehamilan (minimum $1 \mathrm{x}$ trimester pertama, $1 \mathrm{x}$ trimester kedua dan 2x trimester ketiga).

3. Ingatkan istri untuk beristirahat yang cukup, jangan bekerja dan mengangkat barang yang berat.

4. Minta bantuan keluarga dan warga setempat bila suami berhalangan. untuk mengantarkan ke bidan.

5. Segera rujukan jika terjadi komplikasi persalinan.

6. Berikan perhatian khusus kepada istri dan dianjurkan untuk lebih sering memeriksa kehamilan.

b. ANTAR = Siapkan setiap saat: sistem transportasi dan kendaraan serta donor darah.

c. $\mathrm{JAGA}=$ Damping istri pada saat menjelang, selama, dan pasca persalinan.

Untuk menterjemahkan sistem Warga Siaga dan Suami Siaga, maka Desa Siaga dari Kampung Siaga menerapkan 4 sistem yang meliputi:

1. Sistem Informasi/Notifikasi

2. Sistem Transportasi

3. Sistem Donor Darah

4. Sistem Dana
a. DASOLIN
(Dana
Sosial Bersalin) 


\section{b. TABULIN (Tabungan Ibu Koordinator/Ketua \\ Bersalin)}

Keempat sistem tersebut dikembang-kan sebagai upaya merubah perilaku masyarakat dalam mengorganisir kegiatan partisipasi publik.

Secara struktur Kampung Siaga berada di tingkat Rukun Warga atau RW dan dibentuk atas kesepakatan bersama antara pengurus Rukun Tetangga/RT, tokoh masyarakat, tokoh agama, bidan dan pengurus RW. Sedangkan di tingkat Kelurahan Kampung Siaga di koordinir oleh Fasilitator, sedangkan di tingkat Kecamatan masuk dalam sistem kepengurusan LSM Warga Siaga tingkat Kecamatan. Dari 278 Kampung Siaga yang terbentuk di 22 Kelurahan yang ada di Kota Cirebon, hampir 70\% kepengurusan Kampung SIAGA banyak melibatkan kaum pria dan tokoh masyarakat. Untuk men-dampingi fasilitator dalam memberikan motivator dan sosialisasi di tingkat Kelurahan dibantuoleh Dai atau Mubaligh yang pernah mengikuti pelatihan advokasi isu AKI/AKB. Para Dai dan Mubaligh kini membentuk Tim Dai SIAGA.

Adapun susunan pengurus Kampung Siaga di tingkat RW meliputi: Penanggung Jawab

Penasihat
Sekretaris

Bendahara

Koordinator Sistem Informasi/Notifikasi

Koordinator Sistem Donor Darah

Koordinator Sistem Dana

Koordinator Sistem Transportasi

Sedangkan istilah Desa Siaga lebih popular di Kabupaten Cirebon dan Kabupaten Kuningan, karena memang gerakan warga siaganya diarahkan untuk pembentukan Desa Siaga yang ada di tiap Desa. Desa Siaga berada di tingkat Desa dengan melibatkan Bidan Desa, Tokoh Masyarakat, Fasilitator, Masyarakat, dan Kader. Terbentuknya Desa Siaga dibentuk atas hasil musyawarah masyarakat desa difasilitasi oleh Kepala Desa, Bidan Desa dan Fasilitator yang sebelumnya pernah ikut pelatihan Fasilitator Desa Siaga. Desa Siaga juga memiliki 4 sistem, yaitu:

1. Sistem Informasi

2. Sistem Donor Darah

3. Sistem Dasolin

4. Sistem Transportasi 
Keempat sistem ini berjalan sesuai dengan kebutuhan masyarakat desa tersebut, dan merupakan hasil kesepakatan bersama antara masyarakat desa dengan fasilitator. Desa Siaga dibentuk dari hasil kesepakatan bersama untuk mencegah AKI/AKB di desa tersebut. Adapun struktur kepengurusan Desa Siaga biasanya seperti:

Penanggung Jawab

Penasehat

Koordinator/Ketua

Sekretaris

Bendahara

Seksi Notifikasi/Pendataan

Seksi Donor Darah

Seksi Dana

Seksi Sarana Transportasi

Struktur tersebut bersifat sederhana tergantung kebutuhan dan kesepakatan bersama antara masyarakat bidan dan fasilitator desa.

Desa Siaga/Kampung Siaga sangat fleksibel, artinya dari tujuan semula sebagai upaya partisipasi masyarakat dalam menekan AKI/AKB perkembangannya ternyata juga mampu untuk segala bentuk partisipasi masyarakat yang lainnya, seperti pencegahan demam berdarah dan jenis sosialisasi penyakit lainnya. Kampung Siaga terbukti efektif untuk memberikan bantuan gawat darurat, bukan hanya pada persoalan menolong ibu hamil melahirkan dan bayi baru lahir, tapi juga pada persoalan lainnya seperti contoh pada hari Kamis, 19 Agustus 2004, ketika seorang sahabat dari Kabupaten Kuningan salah satu saudaranya mendapat kecelakaan lalu lintas dan harus di rawat di RST Ciremai Cirebon, karena di Kabupaten Kuningan belum ada rumah sakit yang bisa menangani, pada saat itu pasien memerlukan darah, dari golongan darah $\mathrm{AB}$ (yang memang jarang dan sangat sulit mendapatkan darah AB). Namun karena sistem donor darah di Kampung SIAGA sudah bagus, maka dalam waktu 1 jam pasien tersebut dapat dibantu oleh tim dari Kampung SIAGA RW 01 Subur Asih Kelurahan Larangan Kota Cirebon. Padahal pada waktu yang bersamaan para calo darah sudah menawarkan untuk mendapat golongan darah $\mathrm{AB}$ harus berani membayar hingga Rp 300.000,00. Dan Alhamdulillah dengan adanya sistem donor darah di Kampung SIAGA makan untuk mendapat-kan golongan darah $\mathrm{AB}$ didapat secara gratis, tidak membayar sepeserpun. Dari 12 Kampung Siaga di Kelurahan Sukapura Kota Cirebon, 
mampu mengumpulkan dana dasolin dari masyarakat sebesar Rp 5.325.000,00 (Lima juta tiga ratus dua puluh lima ribu rupiah) uang tersebut digunakan untuk membantu ibu hamil yang tidak mampu.

Manfaat lain dari adanya Kampung Siaga ialah dapat membantu mempromosikan pelayanan Bidan, Puskesmas dan juga sebagai agen informasi bagi promosi kesehatan, terutama yang menyangkut kesehatan lingkungan dan masyarakat termasuk juga kesehatan reproduksi yang banyak melibatkan perempuan. Dengan keempat sistem yang dikembangkan di Desa Siaga dan Kampung Siaga ternyata sangat efektif sebagai media silaturahim dan advokasi kesehatan kepada masyarakat, karena melalui Desa Siaga dan Kampung Siaga peran masyarakat yang dalam hal unu pengurus Kampung Siaga dan Fasilitator yang ada di tiap Kelurahan, serta pengurus Desa Siaga mampu menjadi narasumber, motivator, dan subjek langsung yang mempromosikan tentang pentingnya hidup bersih dan sehat, dan masih banyak manfaat lainnya dari sistem Desa Siaga dan Kampung Siaga, yang mungkin tidak bisa saya sebutkan semua-nya di makalah ini. Yang pasti dengan adanya Desa Siaga dan Kampung Siaga masyarakat disadarkan tentang hak kesehatannya dan dilibatkan secara langsung dalam persoalan kesehatan.

Untuk menjalin agar sistem Desa Siaga dan Kampung Siaga berjalan searah dan sepaham dengan dinas, instansi atau lembaga lainnya yang terkait dengan persoalan kesehatan, terutama yang menyangkut persoalan kesehatan reproduksi dan yang lainnya, maka Desa Siaga dan Kampung Siaga juga menjaring kemitraan dengan lembaga lain, bahkan bukan hanya kemitraan tapi juga mengadvokasi agar lembaga lain juga memiliki peran dan misi yang sama dalam melayani masyarakat Kemitraan yang dilakukan di antaranya dengan:

1. UTDC Palang Merah Indonesia (PMI) Kota Cirebon

a. Menjamin tersedianya darah.

b. Memberikan pelayanan yang baik.

c. Membentuk dan membina kelompok donor darah.

d. Membuat jadwal pengambilan darah/donor darah.
e. Mengunjungi calon pendonor darah.
f. Melakukan pengambilan darah secara rutin.

2. RSUD Gunung Djati (sebagai RSUD rujukan) serta Rumah Sakit lainnya di-minta mampu:
a. Menerapkan 3S (Sapa, Salam, Senyum).
b. Memberikan pelayanan yang baik. 

c. Menyampaikan
mekanisme pelayanan yang jelas.
d. Memperbaiki komunikasi didalam RSUD/RS Swasta.

\section{PUSKESMAS/Bidan}

a. Memberikan pelayanan persalinan.

b. Menemani ibu hamil saat rujukan.

c. Membina sistem Kampung Siaga kerjasama dengan fasilitator Kelurahan serta sistem Desa Siaga.

d. Memberikan data ibu hamil ke PMI melalui PMI Anak Ranting.

e. Memperbaharui data di papan siaga.

f.Pemerintah Kota/Kabupaten atau Dinas Kesehatan.

g. Menjadikan program SIAGA sebagai program kesehatan Pemerintah Kota dan Pemerintah Kabupaten.

h. Memasukkan program SIAGA dalam budget APBD.

i. Mengeluarkan kebijakan yang melindungi ibu hamil dan bayi.

j. Warga atau Masyarakat.

k. Membentuk, membangun, memelihara, dan menjalankan sistem SIAGA.

Sistem kemitraan ini dibangun atas kesadaran bersama dari semua lintas sektoral, kendati dalam pelaksanaan masih perlu waktu adanya proses penyadaran peran, namun hampir sekitar $80 \%$ sistem kemitraan ini berjalan.
Sejak Juli hingga akhir Agustus 2004 khusus di Kota Cirebon melalui Gerakan Sayang Ibu atau GSI, sistem Kampung Siaga yang merupakan bagian dari program Warga Siaga ber-integrasi dengan GSI yang selanjutnya dari hasil Lokakarya GSI tingkat Kota Cirebon, muncul kesepakatan bersama program GSI melibatkan langsung peran Warga Siaga, sehingga untuk Satgas GSI tingkat Kecamatan melibatkan Ketua LSM Warga Siaga tingkat Kecamatan menjadi Sekretasris, dan Satgas GSI tingkat Kelurahan, melibatkan Fasilitator Warga Saga di tiap Kelurahan menjadi Ketua Satgas GSI Kelurahan, sementara sistem Kampung SIAGA menjadi prioritas program dalam Gerakan Sayang Ibu di tiap Kelurahan.

Ada beberapa langkah sebelum membangun sistem Desa Siaga atau Kampung Siaga, sebelumnya diadakan pelatihan untuk Fasilitator dan Bidan Puskesmas dengan melibatkan mereka mengikuti pelatihan fasilitator desa siaga dan fasilitator Warga Siaga dengan menggunakan metode Partisipatif. Pelatihan tersebut biasa dilaksanakan memerlukan waktu 3 hari 2 malam dengan jumlah peserta antara 20 hingga 25 orang. Metode yang kami siaokan ialah dengan membangun kesadaran masyarakat melalui identifikasi persoalan yan langsung berkaitan dengan objek tapi juga subjek 
yang mengidentifikasi masalah tersebut, bahkan juga yang merencanakan bagaimana menyelesaikan maslah tersebut, serta membuat RTL untuk dapar dilaksanakn sendiri dan kelompoknya. Dalam metode pelatihan juga disamping menggunakan metode partisipatif ini juga menggunakan proses pembelajaran dari pengalaman orang lain. Ternyata proses pembelajaran meng-gunakan pengalaman orang lebih efektif, disamping peserta mampu menggali persoalan, juga peserta termotivasi dari pengalaman orang lain. Pelatihan untuk fasilitator, bidan dan petugas kesehatan dilakukan dengan biaya yang sangat fleksibel, dan tidak harus menggunakan fasilitas yang mewah, sebab kendati peserta dan trainer menginap namun tidak harus menggunakan fasilitas yang mahal, mungkin lebig tepat cari wisma atau kerjasama dengan lembaga yang memiliki balai latihan kerja. Adapun para trainer biasa dilakukan oleh 2 hingga 3 orang dengan melibatkan unsur kesehatan 1 orang. Honor untuk trainer (di luar transportasi dan akomodasi) juga atas hasil kesepakatan, artinya tidak terlalu mahal asal terlebih dahulu ada kesepakatan yang dijalin tentang prosedur pembiayaan tersebut, yang pasti bagi trainer unsur keter-bukaan lebih utama, karena ini merupakan bekal bagi permulaan gerakan partisipasi, artinya dengan keterbukaan peserta mampu mendesain permasalahan dan menyelesaikan masalahnya. Berikut ini kamu informasikan bentuk jadwal atau agenda pelatihan fasilitator dengan menggunakan Metode Partisipatif:

\section{Hari Pertama:}
a. Pembukaan
b. Coffee Break
c. Sessi 1 : Harapan dan Tujuan Pelatihan
d. Sessi 2 : Potret Kesehatan Ibu dan Bayi di Kabupaten atau Kota
e. Istirahat makan siang
f. Sessi 3 : Mulai menggali masalah
g. Coffee Break
h. Sessi 4 : Menganalisa masalah

\section{Hari Kedua:}

a. Review hari pertama

b. Sessi 5 : Merumuskan masalah 1

c. Coffee Break

d. Sessi 6 :Merumuskan masalah 6

e. Istirahat makan siang

f. Sessi 7 : Memahami peran dan fungsi Fasilitator

g. Coffee Break

h. Sessi 8 : Memahami peran dan fungsi Fasilitator

\section{Hari Ketiga:}

a. Review hari kedua

b. Merencanakan langkah-langkah tindak lanjut 


\section{c. Coffee Break \\ d. Membangun jaringan \\ e. Istirahat makan siang \\ f. Penutup/Pulang}

Kita harus sepakat bahwa masalah kesehatan reproduksi tidak hanya aspek klinis, tapi aspek sosial juga sangat mem-pengaruhi. Kita sadar bahwa persoalan kesehatan reproduksi tidak bisa lepas dari konteks sosial, dimana reproduksi dipengaruhi dan mempengaruhi nilai, etika, agama dan kebudayaan. Secara klinik medis penanganan masalah kesehatan reproduksi tampaknya tidak ada masalah, karena hampir di setiap kota dan kabupaten kini memiliki program yang diarahkan untuk meningkatkan keterampilan tenaga medis, baik dokter, bidan, perawat dan pelayan kesehatan lainnya. Namun masih ada satu hal yang mungkin menjadi persoalan bersama, yaitu bagaimana kita membangun sistem Klinik Sosial sebagai media interaksi masyarakat dengan tim kesehatan untuk bersama-sama membangun kesadaran bersama dalam masalah kesehatan reproduksi. Klinik Sosial bisa jadi merupakan bagian dari salah stu proses pemberdayaan ma-syarakat secara langsung dalam keterlibat-annya menjadi objek dan subjek dari setiap program kesehatan yang diarahkan ke masyarakat. Mungkin hanya sekadar meng-ingatkan bahwa faktor perilaku dan lingkungan sangat dominan dalam mem-pengaruhi keberhasilan peningkatan derajat kehidupan yang bersih dan sehat bagi masyarakat, dibanding faktor keturunan dan pelayanan. Alternatif mewujudkan klinik sosial bisa jadi sitem Kampung Siaga dan Desa Siaga bagi Kota dan Kabupaten merupakan salah satu solusinya. Kenapa tidak kita coba?

\section{DAFTAR PUSTAKA}

Asghar Ali Enginerr. 1994. Hak-hak Perempuan dalam Islam. Yogyakarta: Yayasan Bentang Budaya Yogyakarta.

Mariana Amirudin. 2003. Panduan Untuk Jurnalis "Kesehatan dan Hak Reproduksi Perempuan”. Jakarta: Yayasan YJP Jurnal Perempuan.

Iswarati dan Rahmadewi. 2002. Buku Sumber Untuk Advokasi. Jakarta: BKKBN dan UNFPA.

Annual Report MNH Program. 2002. Cirebon 